\title{
Enfermedad de Steinert: diagnóstico a partir de una arritmia ventricular
}

J. Canales Reina, S. Parejo Guasch*

Médico de Familia. * Residente de $3^{\text {er }}$ año de M edicina de Familiar y Comunitaria.

Centro de Salud Passeig de Sant J oan. ICS. Barcelona

\section{RESUMEN}

La enfermedad de Steinert o distrofia miotóni ca es una afectación multisistémica que se mani fiesta preferentemente en el músculo esquelético, siendo la característica clínica más relevante la debilidad muscular progresiva, la miotonía y la atrofia muscular. En ocasiones las primeras ma nifestaciones no son musculares lo que conlleva un retraso en el diagnóstico. Es necesario reali zar un estudio genético en todos los familiares de riesgo.

Palabras clave: Enfermedad de Steinert. Arrit mia ventricular. Anamnesis.
Steinert disease: diagnosis from a ventricular arrhytmia

\begin{abstract}
The Steinert disease o myotonic dystrophy is a multisystemic afectation that manifest mainly in the squeletic muscle, being the most relevant cli nic characteristic the muscular weakness, the myotonic and the muscular atrophy. Ocasionaly the firsts manifestations are not musculars, in this case can be delate the diagnosis. It is neces sary to make a genetic study to all relatives with risk.
\end{abstract}

Key words: Steinert disease. Ventricular arrhythmia. Anamnesis.

\section{INTRODUCCIÓN}

La distrofia miotónica es una enfermedad que se hereda de forma autosómica dominante y que afecta a diferentes sistemas del organismo. Una característica importante es la gran variabilidad de su expresión clínica, fenómeno que puede observarse dentro de una misma familia. El diagnóstico es clínico y electrofisiológico. El estudio de familiares que sufren la distrofia miotónica es fundamental para el diagnóstico precoz, que nos permitirán incidir en el consejo genético.

\section{CASO CLÍNICO}

Mujer de 25 años que acude a nuestro Centro de Salud remitida desde un club deportivo porque en un chequeo de rutina se le aprecia un pulso arrítmico sin otra sintomatología.

Entre los antecedente personales destaca apendicectomía a los 14 años, niega hábitos tóxicos, ingesta de fármacos y alergias. Profesión puericultora. Entre los antecedentes familiares refiere que la madre está afectada de una miopatía, el padre y cuatro hermanos sanos. Refiere desde hace un año la presencia de tos y expectoración intermitente

Aceptación: 11-03-02 
que no le impide la práctica deportiva habitual, niega la existencia de fiebre, disnea, toracalgia, palpitaciones ni síncope, siendo el resto de la anamnesis anodina. A la exploración física se trata de una paciente de complexión atlética, normocoloreada y con buen aspecto general. La auscultación cardiorrespiratoria denota tonos arrítmicos, sin soplo, ni roce y presencia de roncus en la base del hemitórax derecho modificables con la tos. Abdomen blando sin visceromegalias, no edemas ni adenopatías. Neurológicamente consciente y orientada, discreta paresia distal en la extremidad superior derecha en la región tenar-hipotenar, ligera ptosis parpebral bilateral e incapacidad para silbar, resto de la exploración anodina. Fondo de ojo normal.

Se solicitó un ECG, objetivándose la presencia de extrasistolia ventricular en forma de quatrigeminismo y bradicardia. La radiografía de tórax fue estrictamente normal y la analítica de sangre destacaba CPK 435 (vn=125), hemograma, bioquímica, hormonas tiroideas, enzimas hepáticas y musculares, ANA dentro de la normalidad.

Nos encontramos con una paciente joven con un trastorno en la conducción cardiaca, episodios repetidos de infección respiratoria, con antecedentes familiares de miopatía que unido a la alteración neurológica nos hizo sospechar que sufría una distrofia miotónica o enfermedad de Steinert, diagnóstico que fue confirmado por el servicio de neurología del hospital de referencia. La paciente fue derivada al cardiólogo para la valoración de su arritmia ventricular.

\section{DISCUSIÓN}

El motivo de consulta de nuestra paciente fue el hallazgo casual de una arritmia ventricular durante la realización de un chequeo. La ausencia de otra sintomatología referida por la paciente a priori nos sugería que podría tratarse de una cardiopatía congénita, valvulopatía o ingesta de fármacos, sin embargo la realización de una correcta anamnesis haciendo hincapié en los antecedentes familiares y una cuidadosa exploración física nos ayudó a poner de manifiesto esta enfermedad .

A pesar de que las manifestaciones clínicas de la distrofia miotónica son amplias ${ }^{1,2}$, si el motivo de consulta es la presencia de una arritmia sin estar patentes la miotonía ni la debilidad muscular, el diagnóstico es frecuentemente diferido durante largo tiempo.

La distrofia miotónica de Steinert es una enfermedad autosómica dominante cuyo gen causante se sitúa en el brazo largo del cromosoma $19^{3}$.

Clínicamente se caracteriza por la debilidad muscular y la miotonía. Se ha clasificado en dos formas: la forma moderada cuya evolución es len- tamente progresiva con periodos estacionarios, la debilidad muscular está limitada en antebrazos y dorsoflexores del pie, escasa miotonía sin trastornos del sistema nervioso central, mientras que las cataratas y los trastornos de conducción cardiaca son frecuentes.

La forma clásica que se caracteriza porque la progresión es más rápida y cursa con miotonía florida. La debilidad muscular tiene una distribución característica (facial, mandibular, flexora cervical y periférica), suele haber ptosis parpebral, debilidad de maseteros y orbicular. A diferencia de la distrofia escápulo humeral la cintura escapular se afecta muy tardíamente, a diferencia de otras miopatías la afectación muscular distal de las extremidades es precoz. La miotonía suele aparecer entre los 5 y 25 años y se caracteriza por una contracción involuntaria y mantenida de la musculatura al percutir con el martillo de reflejos, por ejemplo, en la musculatura tenar o al invitar al paciente a contraer un músculo. Estos pacientes suelen tener un coeficiente intelectual bajo, apatía, agresividad, hipersomnia, posiblemente en relación con un aumento de gliosis y una disminución del flujo sanguíneo detectado en estudios con espectroscopia de protones.

La afectación cardiaca es debida a una fibrosis progresiva de las vías de conducción, se manifiesta en forma de arritmias (bloqueo A-V de $1^{\text {er }}$ grado, bradicardia sinusal y bloqueo de rama ${ }^{4}$, hay mayor riesgo de muerte súbita incluso en estadios precoces.

En la afectación respiratoria destaca la hipoventilación por hipotonía diafragmática y aspiraciones. Los trastornos gastrointestinales en forma de disfagia, dolor abdominal inespecífico y diarrea crónica. Atrofia gonadal, alteración en el metabolismo de la glucemia. Cataratas, suelen ser muy frecuentes, se utilizan como marcador para detectar portador. Calvicie frontal en varones.

El curso de la enfermedad es progresivo. Después del diagnóstico de la enfermedad, los pacientes afectos no suelen vivir más allá de 4 décadas, siendo las causas de mortalidad la infección respiratoria y las arritmias cardiacas ${ }^{5}$.

Es fundamental la monitorización de los pacientes con distrofia miotónica mediante ECG anuales para la detección de alteraciones en la conducción cardiaca.

Son situaciones especiales, la embarazada afectada de distrofia miotónica ya que puede presentar complicaciones por la miopatía, que genera un parto lento, hidramnios que sobre todo empeora a partir del $6^{\circ}$ mes y si deben someterse a una anestesia ya que favorece las complicaciones por la afectación de la musculatura respiratoria.

El diagnóstico de la enfermedad de Steinert es básicamente clínico, investigando la presencia de familiares afectos de miopatía. 


\section{Tabla I}

DIAGNÓSTICO DIFERENCIAL DE LA DM CON OTRAS MIOPATÍAS CONGÉNITAS

\begin{tabular}{|c|c|c|c|}
\hline & Miotonía & Debilidad & Localización \\
\hline Enfermedad de Duchene & - & ++ & Proximal \\
\hline Enfermedad de Bercker & - & +++ & Facial \\
\hline Miotonía de Thomsen & +++ & $+1-$ & Facial \\
\hline Distrofia facioescapulohumeral & - & + & Facial. Proximal \\
\hline Distrofia oculofaríngea & - & $+1-$ & Facial. Faríngea \\
\hline Enfermedad de Mc Ardel & - & + & Mialgias. Infantil \\
\hline Paramiotonía congénita & + & - & Relación con frío \\
\hline
\end{tabular}

Los estudios complementarios que puede realizarse son: análisis de sangre que puede poner de manifiesto una elevación de las CPK musculares. Análisis genético del DNA a partir de los leucocitos (permite el diagnóstico prenatal y de familiares a-oligosintomáticos). Estudio neurofisiológico que demostrará la presencia de un patrón miopático, esta prueba será útil en el diagnóstico precoz y en la progresión de la enfermedad.

El diagnóstico diferencial raramente ocasiona problemas, aunque deben considerarse otras miopatías congénitas (Tabla I), la miastenia gravis y la parálisis periódica. En la DM la miotonía es más severa y la amplitud de sintomatología variada de otros órganos nos ayudará al diagnóstico.

La enfermedad de Steinert no tiene un tratamiento específico, básicamente es sintomático con especial énfasis en la rehabilitación y en la psicoterapia. Deberían investigarse cardiológicamente mediante ECG y Eco-Doppler todos los pacientes afectados de distrofia miotónica y tratados en el caso de que su afectación sea severa ${ }^{6}$. Es fundamental hacer un estudio de todos los familiares de riesgo, recomendando el diagnóstico prenatal en todos los embarazos de madres afectadas durante el primer trimestre de la gestación que se realizará mediante biopsia corial, analizando en DNA fetal. Insistir en el consejo genético. En el caso que presentamos la madre estaba afectada de la enfermedad de Steinert y seguía controles en un servicio de Neurología de un Hospital, a pesar de ello no se había realizado un estudio genético a los familiares.

CORRESPONDENCIA:

Juan Canales Reina

$\mathrm{C} /$ Escorial $150,3^{\circ} 1^{\mathrm{a}}$

08024 Barcelona

\section{Bibliografía}

1. Kurt. Isselbacher et al. Harrison. Principios de Medicina Interna. Impreso en España. Interamericana de España. 1994; 2751: 2 .

2. Hoekelman R. Atención Primaria en Pediatría. Ed. Hartcourt España S.A. 1999. p. 423.

3. Harley HG, et al. Unstable DNA sequence in myotonic dystrophy. Lancet 1992; 339: 1125-8.

4. Tokgozoglu LS, Ashizawa A. Cardiac involvement in a large kindred with Myotonic Dystrophy. JAMA 1995; 274 : 813-9.

5. Mathieu J, Allard P, Potvin L, Prevost C, Begin P. A 10-year study of mortality in a cohort of patient with myotonic dystrophy. Neurology 1999; 12; 52(8): 1658-62.

6. Finsterer J, Stollberger C, Blazek G, Spahits E. Cardiac involvement in myotonic dystrophy: a five-year follow-up. Can J Cardiol 2001; 17 (10): 1061-9. 